\title{
AGEING OF RABBIT SPERMATOZOA IN THE MALE TRACT AND ITS EFFECT ON FERTILITY
}

\author{
J. M. TESH* AND T. D. GLOVER \\ Unit of Reproductive Biology, University of Liverpool
}

(Received 23rd September 1968)

\begin{abstract}
Summary. The influence on fertility of the ageing of rabbit spermatozoa in the male tract has been investigated. To age the spermatozoa, the corpus epididymidis was ligated bilaterally so that the inflow of younger spermatozoa into the tail of the epididymis from higher levels of the duct was prevented. Ejaculated semen samples collected from the rabbits at different times after the operation were used for insemination. It was found that the fertilizing capacity of the spermatozoa was lost after 49 days. Losses before implantation increased progressively until 28-dayold spermatozoa were used, but post-implantation losses reached a peak with 35-day-old spermatozoa. After implantation, losses appeared to occur at progressively earlier stages of development as the age of the spermatozoa increased. In the strain of rabbits used, several foetuses were seen to lack gall bladders and to have abnormal skull sutures following the insemination of does with aged spermatozoa.

Throughout the experiment, the motility, morphology and reaction of the spermatozoa to staining with aqueous nigrosin-eosin was examined. The significance and possible causes of adverse changes in ageing spermatozoa are discussed.
\end{abstract}

\section{INTRODUCTION}

The tail of the epididymis is a storage area for mature spermatozoa (Von Lanz, 1924, 1926; Polovtzeva, 1938; Chang, 1945; Ortavant, 1952; Chang \& Schaeffer, 1957), but although the conditions are favourable to their survival, spermatozoa are not preserved indefinitely in a viable state; gradually they age and so lose their vitality (Hammond \& Asdell, 1926; Young, 1929, 1931). There are appreciable differences between species in the length of time spermatozoa can survive in the male tract. In the mouse, fertility is not affected until spermatozoa are 10 to 14 days old (Snell, 1933), whilst in the rat they must be 20 days old (White, 1933) and in the guinea-pig 20 to 35 days old (Young, 1929). In the rabbit, spermatozoa must be over 40 days old before complete sterility results (Hammond \& Asdell, 1926).

Unless the older spermatozoa are eliminated from the male tract quickly and efficiently, their incidence in ejaculated semen is likely to vary according to the

\footnotetext{
* Present address: Toxicology Unit, Beecham Research Laboratories, Betchworth, Surrey.
} 
frequency of sexual activity. This means that after long periods of sexual rest, old or ageing spermatozoa might well preponderate in the first few ejaculates. The evidence is that, if this were to happen, infertility might result, for the work of Young $(1929,1931)$ in the guinea-pig suggests that, even if fertilization were achieved, aged spermatozoa might cause embryonic mortality. It appears that in guinea-pigs, 20- to 25-day-old spermatozoa may give rise to an increase of almost $20 \%$ in the incidence of non-viable embryos.

These effects have not been clearly demonstrated in the rabbit, for Hammond \& Asdell (1926) used the number of pregnancies and the size of litters as criteria of fertility. It was hoped that, by undertaking a more detailed investigation of ageing in rabbit spermatozoa, its influence on prenatal development as well as on fertilizing capacity could be determined. The rabbit has an additional advantage as an experimental animal in that ejaculated semen is readily obtained and appraised, and changes in semen quality can be judged in relation to ensuing levels of fertility.

\section{MATERIALS AND METHODS}

Fifteen adult bucks and ninety-seven does were used. They were of the New Zealand White strain from a closed colony, and varied in weight from 3.75 to $4.50 \mathrm{~kg}$. They were maintained under the same conditions of environment and diet (Diet SG1, Oxoid Ltd, supplemented with hay). Permanent access to drinking water was provided for each animal.

\section{Procedures with male animals}

Bilateral ligation of the epididymis was carried out in each of the bucks used in the experiment. They were anaesthetized with nitrous oxide and halothane (Fluothane, ICI Pharmaceuticals Ltd) which was administered by a face mask using the open circuit method. Nitrous oxide and oxygen in a ratio of $4: 1$ and at a flow rate of 2.5 litres/min were used to induce anaesthesia, and a $5: 2$ ratio of nitrous oxide and oxygen containing 5 to $6 \%$ halothane at a flow rate of $700 \mathrm{ml} / \mathrm{min}$, was used to maintain it.

An incision of approximately $1 \mathrm{~cm}$ in length was made in the scrotal skin and tunica vaginalis on the lateral surface of the scrotal sac. The body of the epididymis and part of the tail of the epididymis were immediately visible. Two ligatures were placed around the distal portion of the body of the epididymis approximately $0.5 \mathrm{~cm}$ apart and the intervening segment was removed. Gare was taken to avoid damage to associated blood vessels (Glover, 1960). There was no handling of the epididymis, except for the small portion that was ultimately removed as part of the operation. The scrotal approach is much less traumatic and therefore preferable to the abdominal approach which involves elevating the testes and subsequently returning them to the scrotum (Glover, unpublished observations).

The bucks used in this experiment were selected for the high quality of their semen. Collections of semen were made using an artificial vagina (Walton, 1958). Control ejaculates were collected from each animal 2 days before operation, and post-operatively they were taken at 7,14 and 21 days from seven 
of the bucks and at 28, 35, 42 and 49 days from the remaining eight animals. In this way spermatozoa were obtained that had been 'aged' in the cauda epididymidis and ductus deferens from 0 to 49 days.

Individual samples taken at any one of the post-operative periods were examined for motility by simple microscopical observation. They were then pooled, diluted to $10 \mathrm{ml}$ with physiological saline and the total concentration of spermatozoa was determined. Motility was again checked after dilution, and smears stained with aqueous nigrosin-eosin (Glover, 1960) were prepared. From these smears, certain morphological features of the spermatozoa and the incidence of eosinophilic forms were examined. Morphologically abnormal spermatozoa included decapitate forms, spermatozoa with coiled tails, distorted mid-pieces and abnormal features of the acrosomes. Although 'temperature-shock' (Hancock, 1951) does not appear to be a problem with rabbit spermatozoa (Wales \& White, 1959), there was the possibility that ageing might render the spermatozoa more susceptible to sharp changes in temperature. For this reason, the stain and equipment were warmed to about $30^{\circ} \mathrm{C}$ before use.

\section{Procedures with female animals}

The does in this experiment were caged singly from 12 weeks of age and on reaching 20 weeks of age they were injected intravenously with 25 i.u. luteinizing hormone (Pregnyl, Organon Laboratories) to induce a state of pseudopregnancy. This terminated with the onset of oestrus 19 to 21 days later (Adams, 1960).

Age-changes in the spermatozoa were then tested by insemination of these does. At each of the eight stages in the 0- to 49-day period of sperm ageing, twelve to fourteen does were each inseminated with $0.5 \mathrm{ml}$ of pooled semen and immediately given a further injection of $\mathbf{L H}$. On every occasion, half the does in a group were selected at random and 48 to $60 \mathrm{hr}$ afterwards they were killed with a rapid injection of sodium pentobarbitone (Nembutal, Abbott Laboratories). Eggs were flushed from these animals and examined for cleavage which was taken as evidence of fertilization (Venge, 1950; Adams, 1956; Tesh, 1966). The eggs were first examined fresh and then, after fixation with acetic alcohol, they were stained with aceto-carmine (Tesh, 1966). The fertilization rate of the spermatozoa (i.e. the percentage of eggs fertilized) at each of the eight periods of ageing was thus determined and was expressed as a mean figure for each period. The does concerned were referred to as Group 1. The remaining does, Group 2, were used to assess effects on post-fertilization development. For this, the does were examined by laparotomy on Day 10 following the ovulatory injection of $\mathbf{L H}$, in order to determine the number of implantation sites. At this stage, implantations were seen as discrete swellings 12 to $21 \mathrm{~mm}$ in diameter (Adams, 1960). When the implantation sites had been counted, the abdomen was closed using sterile braided surgical silk, size 00 . This procedure took between 12 and $20 \mathrm{~min}$ to complete so that possible adverse effects on foetuses were reduced to a minimum. Nitrous oxide and halothane anaesthesia was again used since it is known that barbiturates might, in some circumstances, affect foetuses (Tesh, unpublished observations; Champakamalina \& Appaswamy Rao, 1967). 
The pregnancy was allowed to continue until Day 29 when the does were killed and detailed examination of the contents of each uterus was made. The number, weight and sex of live foetuses were recorded together with the weights of both normal and atrophic placentae. The number, weight and size of dead foetuses were noted and, if present, their position in the uterus was recorded. Live foetuses were killed with an overdose of pentobarbitone sodium and a detailed macroscopical examination was then performed. Foetuses showing abnormal features, particularly skeletal deformities, were fixed and stained with a modification of Dawson's staining technique (Tesh \& Worsley, unpublished observations). The ovaries of each doe were removed and the corpora lutea were counted. From all these data, post-fertilization failure was estimated.

By multiplying fertilization rate, as assessed from animals in Group 1, by the number of corpora lutea counted in Group 2, an estimate was made of fertilization rate in Group 2 does. The number of implantation sites seen on Day 10 and the number of live foetuses on Day 29 were each divided by this estimate in order to calculate both pre-implantation failure and post-implantation loss. The calculations were based as follows:

$$
\begin{aligned}
\% \text { Fertilization } & =\frac{\text { No. of eggs fertilized }}{\text { Total no. of eggs obtained }} \times 100 \\
\% \text { Implantations } & =\frac{\text { No. of implantations }}{\text { Estimated no. of eggs fertilized }} \times 100 \\
\% \text { Live foetuses } & =\frac{\text { No. of live foetuses at Day } 29}{\text { Estimated no. of eggs fertilized }} \times 100
\end{aligned}
$$

From these calculations, failure in fertility could be defined as:

$$
\begin{aligned}
\text { Fertilization failure } & =100 \text { minus } \% \text { fertilization } \\
\text { Pre-implantation failure }= & \text { Estimated no. of eggs fertilized minus No. of im- } \\
\text { plantation sites } & \\
\text { Post-implantation loss } & \begin{array}{l}
\text { No. of implantation sites minus No. of live } \\
\text { foetuses at Day } 29
\end{array}
\end{aligned}
$$

Further refinement, according to the criteria of Adams (1962), involved a more precise definition of the stage of post-implantation failure. Damage that occurred shortly after implantation resulting in complete resorption by Day 29 was called 'early' loss, and that occurring between this time and about Day 17 of gestation was considered as 'middle' loss. This was recognized on Day 29 by the presence of atrophic placentae. 'Late' loss represented damage occurring later than Day 17 and this usually gave rise to dead foetuses.

\section{RESULTS}

\section{Effects on fertilization}

Text-figure 1 shows data obtained from animals in Group 1 and illustrates the influence of ageing in spermatozoa on the fertilization rate. This was found to be unaffected until 28-day-old spermatozoa were used but between these and 35-day-old spermatozoa, the fertilization rate decreased dramatically from 
$73.8 \%$ to $21.9 \%$. Thereafter, the decrease continued at a slower rate, until 49-day-old spermatozoa were shown to have completely lost their capacity to fertilize (Text-fig. 1). Even so, 49-day-old spermatozoa were seen in the zona pellucida and perivitelline space of uncleaved eggs, showing that some of them were at least capable of reaching the site of fertilization and penetrating the envelopes of the egg.

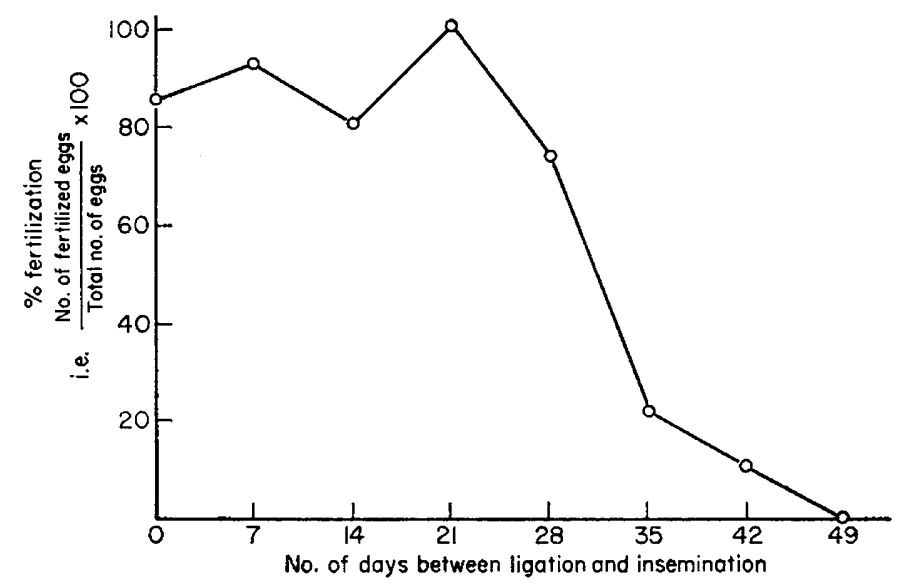

TEXT-FIG. 1. The effect of ageing of spermatozoa on fertilization rate.

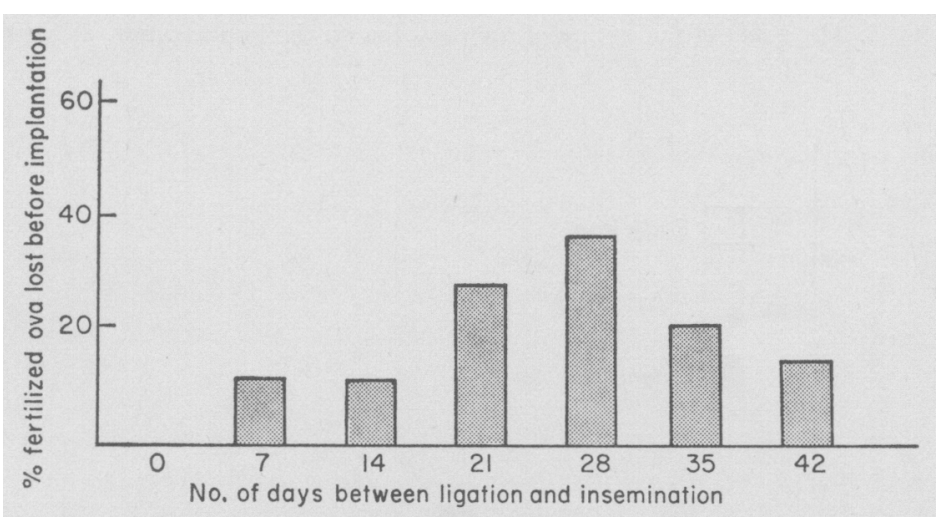

Text-Fig. 2. The effect of ageing of spermatozoa on pre-implantation loss.

Effects on pre-implantation development

The extent of disintegration or death of conceptuses before implantation is shown in Text-fig. 2. There was no pre-implantation loss in control animals but in those inseminated with spermatozoa from operated bucks, it increased progressively with the increasing age of the spermatozoa. A maximum of $38.3 \%$ was reached with 28-day-old spermatozoa but 42-day-old spermatozoa caused only $16.4 \%$ loss. There appeared to be no effect on the actual number of implantation sites, until the spermatozoa were 28 days old. Between 21 and 28 days of ageing, the mean number of implantation sites decreased from 9.0 to $5 \cdot 8$. This rapid decline in implantation rate continued until fertility was completely lost after 49 days of ageing (Text-fig. 3). 
Effects on post-implantation development

Post-implantation loss was calculated as the percentage of implantations lost before autopsy on Day 29 of gestation, and the results are shown in Text-fig. 4. It seems that the overall post-implantation loss increases when progressively older spermatozoa are used, but when spermatozoa of more than 35 days of age are used this loss appears to decline.

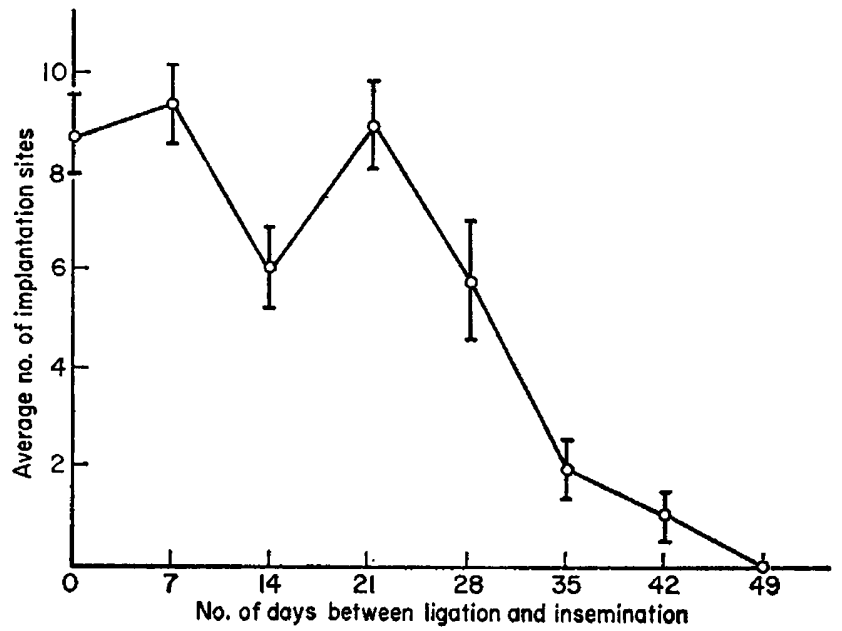

TEXT-FIG. 3. The effect of the ageing of spermatozoa on the implantation of blastocysts.

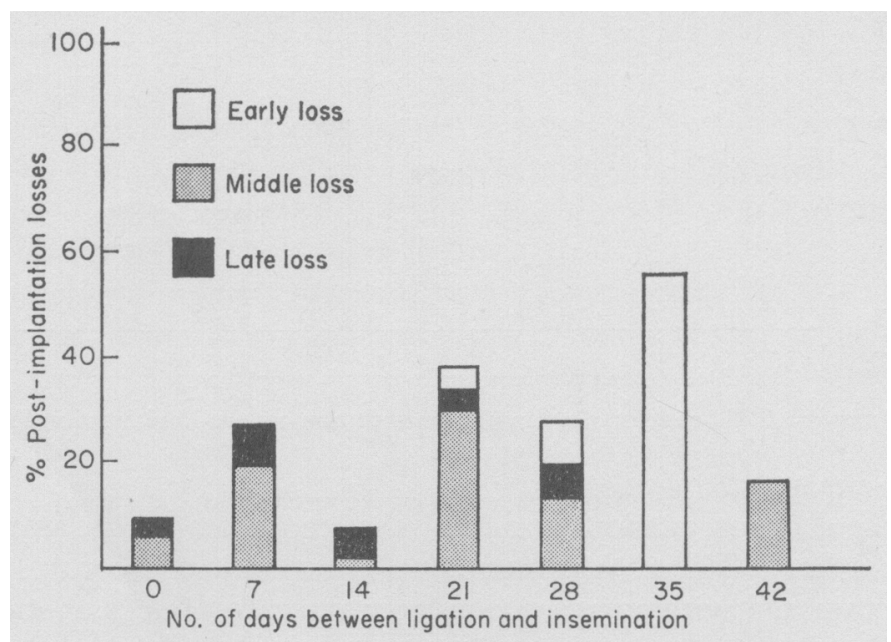

TEXT-Fig. 4. The effect of the ageing of spermatozoa on post-implantation loss.

When the distribution of post-implantation losses was examined, it was found that, when the spermatozoa had been aged for up to 14 days, the loss occurred at the 'middle' and 'late' stages of development only. When the time of ageing was extended beyond this, there was some 'early' loss and this gradually increased to a peak of $57 \cdot 2 \%$ with 35 -day-old spermatozoa. Increased 'middle' 
losses were associated with this 'early' loss, but when the spermatozoa had been aged for 35 days or longer there was no loss at the 'late' stage of development.

The mean number of foetuses per female showed a progressive decrease as age of the spermatozoa increased, and became significantly different from the controls when the spermatozoa had been aged for 28 days $(P<0 \cdot 05)$. Between 28 and 35 days of ageing, the decrease became more rapid and the mean number of foetuses per female declined abruptly from $4 \cdot 1$ to $0 \cdot 8$. The number was maintained at this level until fertility was entirely lost at 49 days (Text-fig. 5).

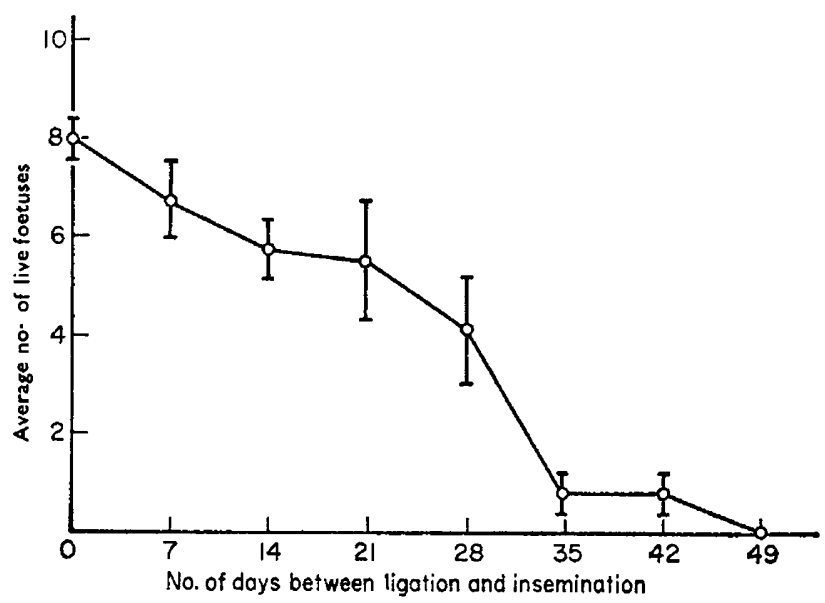

Text-Fic. 5. The effect of the ageing of spermatozoa on the number of live foetuses present in the uterus on Day 29 of pregnancy.

Although there was no difference in mean foetal weights caused by ageing spermatozoa, a highly significant negative linear regression was established between mean foetal weight and the number of foetuses in a litter.

No significant differences in the ratio of male to female foetuses occurred at any stage but the incidence of foetuses without a gall-bladder, and particularly those with abnormal parietal skull sutures, did seem to be related to increasing age of the spermatozoa.

\section{Characteristics of spermatozoa}

Examination of the spermatozoa before insemination revealed that up to 28 days following ligation, there was no change in motility or in the incidence of eosinophilic spermatozoa but that between 28 days and 49 days, there was a decline in motility and an increased proportion of eosinophilic spermatozoa. This, together with other semen characteristics, is shown in Table 1.

The percentage of unstained spermatozoa with coiled tails was relatively constant in semen samples until the 28th day of ligation, when it suddenly increased from $2.5 \%$ to $23.0 \%$. This was reversed at Day 35 when a marked increase in the incidence of stained and decapitate spermatozoa took place. It may be taken, therefore, that after this time ejaculates contained a preponderance of dead spermatozoa. 
TABLE 1

GHARACTERISTICS OF SPERMATOZOA AGED IN MALE TRACT

\begin{tabular}{|c|c|c|c|c|c|c|c|c|c|}
\hline \multirow{2}{*}{$\begin{array}{c}\text { No. days } \\
\text { aged }\end{array}$} & \multirow[b]{2}{*}{ Motility } & \multicolumn{4}{|c|}{ Unstained } & \multicolumn{4}{|c|}{ Stained } \\
\hline & & Normal & $\begin{array}{c}\text { Coiled } \\
\text { tails }\end{array}$ & Decapitates & $\begin{array}{c}\text { Other } \\
\text { abnormalities }\end{array}$ & Normal & $\begin{array}{l}\text { Coiled } \\
\text { tails }\end{array}$ & Decapitates & $\begin{array}{c}\text { Other } \\
\text { abnormalities }\end{array}$ \\
\hline $\begin{array}{r}0 \\
7 \\
14 \\
21 \\
28 \\
35 \\
42 \\
49\end{array}$ & $\begin{array}{c}++++ \\
++++ \\
++++ \\
++++ \\
++++ \\
++++ \\
+++ \\
++\end{array}$ & $\begin{array}{l}81 \cdot 0 \\
78.5 \\
82.0 \\
79.5 \\
52.5 \\
32.0 \\
47.8 \\
11.0\end{array}$ & $\begin{array}{r}1.0 \\
0.5 \\
1.7 \\
2.5 \\
23.0 \\
3.8 \\
2.8 \\
6.6\end{array}$ & $\begin{array}{l}1.0 \\
1.0 \\
0.0 \\
0.0 \\
0.0 \\
0.5 \\
0.5 \\
0.4\end{array}$ & $\begin{array}{l}2.0 \\
0.0 \\
3.7 \\
1.0 \\
0.5 \\
0.5 \\
0.0 \\
0.0\end{array}$ & $\begin{array}{r}12 \cdot 0 \\
16 \cdot 0 \\
8 \cdot 6 \\
9 \cdot 0 \\
7 \cdot 5 \\
31 \cdot 1 \\
24 \cdot 9 \\
30 \cdot 8\end{array}$ & $\begin{array}{r}1.0 \\
0.5 \\
0.0 \\
4.0 \\
3.5 \\
2.8 \\
5.0 \\
15.6\end{array}$ & $\begin{array}{r}2.0 \\
3.5 \\
3.0 \\
4.0 \\
11.5 \\
29 \cdot 3 \\
20.0 \\
35.6\end{array}$ & $\begin{array}{l}0.0 \\
0.0 \\
1.0 \\
0.0 \\
1.5 \\
0.0 \\
0.0 \\
0.0\end{array}$ \\
\hline
\end{tabular}

\section{DISCUSSION}

This work confirms earlier evidence in laboratory animals (Hammond \& Asdell, 1926; Young, 1929, 1931; White, 1933) that infertility may be caused by spermatozoa that have been artificially aged in the male tract for more than about 3 weeks but does not support the view of Hammond \& Asdell (1926) that, in the rabbit, ageing in spermatozoa causes no increase in embryonic death. These authors, however, used successful pregnancies as their indicator of fertility and their comments on embryonic loss were based on two does only. Young (1931) found that, in the guinea-pig, an increased incidence of foetal resorptions and abortion was associated with the use of aged spermatozoa, but that this was not apparent when the ability to produce live young was taken as the only criterion of fertility. It does seem, therefore, that some of the effects of ageing in spermatozoa may not become apparent until after implantation of the blastocyst, but, in the rabbit at least, there has hitherto been no clear information on this or on how the ageing of spermatozoa might affect fertilization or pre-implantation development.

The present experiment has provided information on these points, though the precise cause of events is obscure. No firm conclusion can be drawn from the preimplantation losses because of variability and possible error incurred by the method of calculation. In the case of post-implantation losses, the age of the spermatozoa seemed to be inversely related to the age of the embryos that were lost. It must be assumed, therefore, that some of the earliest changes in the ageing of spermatozoa concern the genome. These changes are distinct from, if additional to, presumed deterioration of the acrosome which will affect sperm penetration and, if widespread, will ultimately cause total failure of fertilization. Ageing of bull spermatozoa in vitro has been shown to bring about a change in the reaction of the spermatozoa to Feulgen staining and to influence prenatal losses (Salisbury, Birge, de la Torre \& Lodge, 1961; Salisbury, 1967) and there is evidence also that, in the rabbit, ageing in vivo of epididymal spermatozoa influences the DNA content of the spermatozoa (Bouters, Esnault, Salisbury \& Ortavant, 1967). There is, thus, considerable support for the notion that the ageing of spermatozoa affects their DNA content.

The present findings on the influence of age on sperm motility, morphology 
and permeability to eosin, are largely in agreement with those of Gaddum (1965), except that, in the present work, signs of degeneration in the spermatozoa were observed sooner. Ejaculated spermatozoa were examined here, however, rather than epididymal spermatozoa. It appears that spermatozoa rendered effete by being aged in the tail of the epididymis, die and disintegrate in the ductus deferens or during ejaculation. There is evidence in the guinea-pig that the ductus deferens may not be as favourable to sperm survival as the tail of the epididymis (Simeone \& Young, 1931).

If old spermatozoa do disintegrate in the ductus deferens, poor semen quality could be an early outcome of prolonged sexual rest unless aged spermatozoa could be removed very efficiently. On the other hand, if spermatozoa degenerate most rapidly in the tail of the epididymis, the possible effects of continence on the quality of ejaculates would be less evident since there would be more time for mixing of spermatozoa in the tract (Orgebin-Crist, 1965) and for their absorption or removal.

Amann \& Almquist (1962) held the view that bovine spermatozoa are eventually absorbed from the tail of the epididymis, but Gaddum \& Glover (unpublished findings) have not been able to confirm this in rabbits. Roussel, Stallcup \& Austin (1967) showed that decapitate spermatozoa may be phagocytosed in the cauda epididymidis of bulls, rabbits and monkeys and this undoubtedly supports the findings of Amann \& Almquist (1962). By contrast, Lino, Braden \& Turnbull (1967) believed that in rams, spermatozoa are removed in the urine during sexual abstinence at a rate which corresponds to sperm production. Species and individual differences may explain, in part at least, the conflicting results obtained by different workers.

Walton (1933) thought that the first few ejaculates after sexual rest might contain an excess of poor quality spermatozoa, but this was not substantiated by Gunn (1936) in rams. Nevertheless, this sort of effect has been reported in the ram by Phillips \& McKenzie (1934) and McKenzie \& Berliner (1937), and also in the bull by Webster (1932) and Herman \& Swanson (1941), in the stallion by Polowzow (1927) and in the boar by Anderson (1945). While adverse effects caused by old spermatozoa are also demonstrated by the present work, it cannot be assumed that prolonged sexual rest will inevitably lead to subfertility. It is by no means clear how far the present work reflects changes in spermatozoa that occur in the normal intact animal. In such an animal, not only younger spermatozoa but also tubular fluid can freely flow into the tail of the epididymis, and when normal mixing of spermatozoa is permitted, their rate of ageing might be effectively reduced. Even so, an egg might at any time be fertilized by an abnormally old spermatozoon, so that it is valuable to know what possible effects might result.

A significant finding in this investigation was that fertility was impaired even though the number of actively motile and ostensibly normal spermatozoa was always in excess of the 0.5 to 1 million needed for maximum fertility (Wales, Martin \& O'Shea, 1965; Hupp, personal communication). This was well shown when 49-day-old spermatozoa were tested. No fertilized ova were recovered from the does in spite of the presence of more than 3 million apparently normal spermatozoa in the inseminate. 
Thus, although peak pre-implantation loss coincided with an increase in the incidence of spermatozoa with coiled tails in ejaculates, and the highest level of post-implantation loss was associated with an increase in the proportion of eosinophilic and decapitate spermatozoa, these abnormalities were not in themselves solely responsible for the infertility caused. It is suggested that they also indicated some deficiency in the apparently normal spermatozoa in the same ejaculates. In this way, it is believed, the abnormal spermatozoa revealed a more generalized deterioration of semen quality.

\section{ACKNOWLEDGMENTS}

The work was financed by the Population Council. We wish, in addition, to thank Mr J. J. Grimshaw for his advice on the statistical analysis of data and Mrs G. Boyd for technical assistance.

\section{REFERENCESS}

ADAms, C. E. (1956) A study of fertilization in the rabbit. The effect of post-coital ligation of the Fallopian tube or uterine horn. F. Endocr. 13, 296.

Adams, G. E. (1960) Studies on prenatal mortality in the rabbit, Oryctolagus cuniculus. The amount and distribution of loss before and after implantation. F. Endocr. 19, 325.

Adams, C. E. (1062) Studies on prenatal mortality in the rabbit, Oryctolagus cuniculus. The effect of transferring varying numbers of eggs. F. Endocr. 24, 471.

Amann, R. P. \& Almouist, J. O. (1962) Reproductive capacity of dairy bulls. VI. Effect of unilateral vasectomy and ejaculation frequency on sperm reserves; aspects of epididymal physiology. 7. Reprod. Fert. 3, 260.

ANDERson, J. (1945) The semen of animals and its use for artificial insemination. Edinburgh Imp. Bureau of Anim. Breeding and Genetics.

Bouters, R., Esnault, G., Salisbury, G. W. \& Ortavant, R. (1967) Discrepancies in analyses of DNA in rabbit spermatozoa involving Feulgen staining (Feulgen-DNA) and ultraviolet light absorption (UV-DNA) measurements. F. Reprod. Fert. 14, 355.

Champakamalina, A. V. \& Appaswamy Rao, M. (1967) Foetal resorption in barbital sodium treated pregnant rats. Current Science, No. 1, 3.

ChANG, M. C. (1945) The sperm production of adult rams in relation to frequency of semen collection. F. agric. Sci., Camb. 35, 243.

Chang, M. C. \& Schaefrer, D. (1957) Number of spermatozoa ejaculated at copulation, transported into the female tract, and present in the male tract of the golden hamster. 7 . Hered. 48, 107.

Gaddum, P. (1965) Some aspects of postnatal development and function in the epididymis of the rabbit. Ph.D. thesis, University of Liverpool.

Glover, T. D. (1960) Spermatozoa from the isolated cauda epididymidis of rabbits and some effects of artificial cryptorchidism. F. Reprod. Fert. 1, 121.

Gunv, R. M. C. (1936) Fertility in sheep. Artificial production of seminal ejection and the characters of the spermatozoa contained therein. Rep. Coun. scient. ind. Res. Aust. No. 94.

Hammond, J. \& Asdeli, S. A. (1926) The vitality of the spermatozoa in the male and female reproductive tracts. Br. 7. exp. Biol. 4, 155.

Hancock, J. L. (1951) A staining technique for the study of temperature-shock in semen. Nature, Lond. $167,323$.

Herman, H. A. \& Swanson, E. W. (1941) Variations in dairy bull semen with respect to its use in artificial insemination. Res. Bull. Mo. agric. Exp. Stn, No. 326. Anim. Breed. Abstr. 10, 27.

Lino, B. F., Braden, A. W. H. \& Turnbule, K. E. (1967) Fate of unejaculated spermatozoa. Nature, Lond. 213, 594.

McKenzie, F. F. \& Berliner, V. (1937) The reproductive capacity of rams. Res. Bull. Mo. agric. exp. $\operatorname{Sin}$, No. 265.

Orgebin-CRIST, M. C. (1965) Passage of spermatozoa labelled with thymidine- ${ }^{3} \mathrm{H}$ through the ductus epididymidis of the rabbit. F. Reprod. Fert. 10, 241.

Ortavant, R. (1952) Recherches sur la spermatogénèse des animaux domestiques. Étude des réserves chez le bélier. C.r. Séanc. Soc. Biol. 146, 1086.

Philitps, R. W. \& McKenzie, F. F. (1934) The thermo-regulatory function and mechanism of the scrotum. Res. Bull. Mo. agric. exp. Stn, No. 217. 
PoLowzow, W. (1927) Die Spermatozoenproduktion beim Pferde. Uber den Einfluss der haufingen Kohabitationen auf die Spermienproduction. Pfïgers Arch. ges. Physiol. 218, 374.

Polovtzeva, V. V. (1938) The rate of movement and the time of maturation of spermatozoa in the epididymis of the ram. Dokl. Akad. Seljskoloz. Nauk. 15/16, 43.

Roussel, J. D., Stallcup, O. T. \& Austin, C. R. (1967) Selective phagocytosis of spermatozoa in the epididymis of bulls, rabbits and monkeys. Fert. Steril. 18, 509.

Salisbury, G. W. (1967) Ageing phenomena in spermatozoa. III. Effect of season and storage at $-79^{\circ}$ to $-88^{\circ} \mathrm{C}$ on fertility and prenatal losses. F. Dairy Sci. 50, (10), 1683.

Salisbury, G. W., Birge, W. J., de la Torre, L. \& Lodge, J. R. (1961) Decrease in nuclear Feulgen positive material (DNA) upon ageing in in vitro storage of bovine spermatozoa. 7 . biophys. biochem. Cytol. 10, 353.

Simeone, F. A. \& Young, W. C. (1931) A study of the function of the epididymis. IV. The fate of nonejaculated spermatozoa in the genital tract of the male guinea pig. F. exp. Biol. 8, 163.

SNeLL, G. D. (1933) X-ray sterility in the male house mouse. F. exp. Zool. 65, 421.

TESH, J. M. (1966) Effect of time of insemination and superovulation on fertilization in the rabbit. 7. Endocr. 35, 28.

VENGE, O. (1950) Studies of the maternal influence on the birth weight in rabbits. Acta zool., Stockh. 31, 1.

Von Lanz, T. (1924) Die Nebenhoden einiger Säugetiere als Samenspeiches. Verh. anat. Ges. Vers. 33, 106.

VoN LANZ, T. (1926) Úber Bau und funktion des Nebenhodens und seine Abhängigkeit von der Keimdruse. Z. Anat. EntwGesch. 80, 177.

Wales, R. G., Martin, L. \& O'SheA T. (1965) Effect of dilution rate and of the number of spermatozoa inseminated on the fertility of rabbits ovulated with chorionic gonadotrophin. F. Reprod. Fert. 10, 69 .

Wales, R. G. \& White, I. G. (1959) The susceptibility of spermatozoa to temperature shock. $\mathcal{F}$. Endocr. 19, 211.

Walton, A. (1933) The technique of artificial insemination. Imperial Bureau of Animal Genetics. As cited by Gunn (1936), p. 84.

Walton, A. (1958) Improvement in the design of an artificial vagina for the rabbit. F. Physiol., Lond. $143,26 \mathrm{P}$.

Webster, W. M. (1932) Bovine sterility in New Zealand. Aust. vet. F. 8, 199.

WhITE, W. E. (1933) The duration of fertility and the histological changes in the reproductive organs after ligation of the vasa efferentia in the rat. Proc. R. Soc. B, 13, 544.

Young, W. C. (1929) A study of the function of the epididymis. II. The importance of an ageing process in sperm for the length of the period during which fertilizing capacity is retained by sperm isolated in the epididymis of the guinea-pig. F. Morph. Physiol. 48, 475.

Young, W. C. (1931) A study of the function of the epididymis. III. Functional changes undergone by spermatozoa during their passage through the epididymis and vas deferens in the guinea pig. 7. exp. Biol. 8, 151 . 